\title{
INVESTIGAÇÃO SOBRE A IDENTIDADE PROFISSIONAL EM ALUNOS DE LICENCIATURA EM CIÊNCIAS BIOLÓGICAS
}

\author{
Investigating on into the professional identity \\ of future biological sciences teachers
}

\author{
Fernanda da Rocha Brando ${ }^{1}$ \\ Ana Maria de Andrade Caldeira ${ }^{2}$
}

Resumo: A presente pesquisa apresenta as perspectivas de atuação profissional de alunos do curso de Licenciatura em Ciências Biológicas de uma universidade pública do estado de São Paulo. Por meio de entrevistas semiestruturadas, levantamos as expectativas desses alunos em relação ao curso que frequentam e qual identidade construíram como parte do imaginário que compõe o ethos. Verificamos que o curso de licenciatura pesquisado pouco contribui para a construção de uma identificação dos alunos com a profissão de professor de Biologia e/ou Ciências e, apesar de constituir-se em um curso de formação para tal, acentua a construção da imagem do cientista- pesquisador nas áreas básicas da Biologia.

Palavras-chave: Formação inicial de professores de Biologia. Identidade profissional. Semiótica peirceana.

\begin{abstract}
The current research presents the professional perspectives of the students majoring in Biological Science in a public university of São Paulo state. The students' perspectives related to that course, have been identified by means of semi structured interviews looking at the identity they have formed as part of how they imagine the ethos of Biology. We have verified that the course which has been surveyed, has contributed little to the construction of identification by the students with the job of Biology or Science teaching. Despite that, the course aims at such a formation of teachers, and it highlights the formation of an image of the scientist-researcher in the basic field areas of Biology.
\end{abstract}

Keywords: Initial formation of Biology teachers. Professional identity. Peirce's semiotic.

\footnotetext{
${ }^{1}$ Doutoranda do Programa em Educação para a Ciência da Faculdade de Ciências, Universidade Estadual Paulista (Unesp). Bauru, SP. Apoio Capes. frochabrando@fc.unesp.br

${ }^{2}$ Livre docente. Professora adjunta do Departamento de Educação e do Programa de Pós-Graduação em Educação para a Ciência, Faculdade de Ciências, Universidade Estadual Paulista (Unesp). Bauru, SP. anacaldeira@fc.unesp.br
}

${ }^{1}$ Rua Cláudio Correia, 374

Vilagio di Roma - Jaú, SP, Brasil

$17.210-868$ 
Brando, F. R.; Caldeira, A. M. A.

\section{Introdução}

Ao refletirmos sobre em que condições ocorre a escolha por uma profissão, verificaremos que esta se dá, não raro, em um momento bem crítico: a idade em que se escolhe "o que quer fazer" ocorre por volta dos 17 a vinte anos, momento em que têm-se poucas "experiências de vida" e se conhece insuficientemente a práxis das profissões de modo geral. Além disso, esse período é característico da adolescência, em que mudanças físicas e psicológicas estão ocorrendo de maneira rápida.

Romero (1997, p. 35) explica que a escolha profissional se dá sob aspectos objetivos e subjetivos, "o indivíduo procura identificar quais as representações sociais relativas à profissão escolhida e procede a uma auto-avaliação, buscando detectar características pessoais condizentes com o perfil profissional esperado". Destaca a importância de conhecer como a realidade de uma profissão é introjetada pelo indivíduo e como interfere na sua escolha e formação profissional.

Sobre a profissão docente, observamos que a figura do professor está presente precocemente na vida de qualquer cidadão. Devemos destacar que o professor é "devir", que constrói valores, crenças, atitudes e hábitos, o que o faz agir em razão de um tipo de opção pessoal que o distingue de outros: sua identidade. Aliadas a essa estão os anseios, motivações, expectativas, interesses, atitudes e hábitos socioculturalmente adquiridos que determinam o modo de ser de cada profissional. "A identidade permeia o modo de estar no mundo e no trabalho dos homens em geral" e, se tratando da profissão docente, "afetando suas perspectivas perante sua formação e as suas formas de atuação profissional" (GATTI, 1996, p. 85).

Sabemos que os cursos de licenciatura em Ciências Naturais (Biologia, Física e Química), estruturados com possibilidades de formação concomitante com a pesquisa em áreas específicas de atuação do biólogo, físico e químico, propiciam muitas vezes ao aluno identificar-se mais como pesquisador nessas áreas do que como professor ou pesquisador em ensino, apesar da opção no vestibular por um curso de formação de professor.

O objetivo geral desta pesquisa foi avaliar quais as concepções profissionais engendradas pelos alunos do curso de Licenciatura em Ciências Biológicas no decorrer de sua formação inicial. Entre os objetivos específicos, buscamos: (1) relacionar as concepções iniciais de biólogo e de professor presentes nos alunos; (2) analisar quais os interpretantes gerados pelos alunos sobre essas concepções no decorrer da formação inicial (3) e se essas influenciaram, ou não, a construção de uma identidade profissional; (4) verificar se o curso de Licenciatura em Ciências Biológicas favorece a formação de identidade de professor de Ciências Biológicas nos referidos alunos.

Por meio de entrevistas semiestruturadas, levantamos as expectativas desses alunos em relação ao curso que frequentavam e qual a identidade que construíram como parte do imaginário que compõe o ethos. Utilizamos, para tanto, a pesquisa qualitativa, referenciais teóricos sobre o conceito de identidade. Em relação à análise dos dados coletados, utilizamos o referencial teórico da semiótica peirceana. 
Investigação sobre a identidade profissional...

\section{A formação identitária do biólogo e do professor}

\section{A questão da identidade}

Considerando a identidade como uma fusão dinâmica de traços que caracterizam um indivíduo ou objeto em determinado tempo e lugar, Silva (1995, p. 31-2) revela que:

Desejos, ações, pensamentos, sentimentos etc. são conjugados ou fundidos ao longo da existência da pessoa, permitindo que outras pessoas a diferenciem e reconheçam-na em sociedade. Assim, identidade, individualidade e singularidade apresentam significados muito próximos cujos matizes são difíceis discernir.

Para Ciampa (1991, p. 72) "é do contexto histórico e social em que o homem vive que decorrem suas determinações e, conseqüentemente, emergem as possibilidades ou impossibilidades, os modos e as alternativas de identidade". Relata que nos conhecemos a partir de semelhanças e diferenças que observamos nos outros indivíduos. Assim: "O conhecimento de si é dado pelo conhecimento recíproco dos indivíduos identificados através de um determinado grupo social que existe objetivamente, com sua história, suas tradições, suas normas, seus interesses etc." (CIAMPA, 1991, p. 64)

É no interior dessa realidade complexa que os jovens constroem suas identidades e procuram valorar suas escolhas.

\section{Identificar-se como professor}

Para fazermos nossa escolha profissional, temos de optar - dentre um rol diversificado de atividades, muitas vezes pouco conhecidas no momento da opção - por uma profissão que, no nosso imaginário, contente-nos e proporcione um reconhecimento sociocultural que possa refletir condições dignas de profissionalismo que garanta sobrevivência e assegure a manutenção do status de profissão.

O que observamos nas profissões instituídas é que o status profissional está socioculturalmente fundamentado, ou seja, as profissões foram desenvolvidas, através do tempo, por "um corpus de conhecimentos especializados, bem demarcados, científicos e padronizados, transmitidos pela educação profissional e pela prática clínica” (GAUTHIER, 1998, p. 71).

Contudo, tratando-se da profissão docente, há certa preocupação em relação ao processo de ensino e aprendizagem que ocorre em sala de aula. Muitas vezes, encontramos no ambiente escolar, como revela Gauthier (1998), ofícios sem saberes e saberes sem ofício. Ofício sem saberes demarcam atividades docentes exercidas que não revelam saberes pedagógicos específicos, aqueles que lhes são inerentes. Mesmo com diversos estudos relativos a essa temática, ainda há dificuldade na definição desses saberes, exigindo, para isso, reflexão sobre esses objetos. Já os saberes sem ofício são aqueles saberes da educação que não levam em consideração as condições concretas do exercício do magistério. Em outras palavras, são saberes produzidos sem o ofício capaz de colocá-los em prática. São pertinentes em si mesmo, mas não são reexaminados à luz do contexto real e complexo da sala de aula. Para o autor, faz-se 
Brando, F. R.; Caldeira, A. M. A.

necessário, no ofício de ensinar, um reservatório de saberes, contrariando o senso comum que acredita que: basta saber o conteúdo, ter talento, intuição, conhecimento cultural abrangente e domínio sobre os alunos, para que haja uma aprendizagem significativa.

O reservatório de saberes citados pelo autor destaca: Saberes disciplinares (a matéria, o conteúdo específico); Saberes curriculares (o programa); Saberes das Ciências da Educação; Saberes da tradição pedagógica (o uso); Saberes experienciais (toda experiência que o professor adquire ao longo de sua jornada docente); Saberes da ação pedagógica (são os saberes experienciais que o professor consegue internalizar para que outros professores possam tê-los como modelos) (GAUTHIER, 1998).

Romero (1997) descreve aspectos importantes sobre a crescente proletarização da atividade docente: (a) a profissão de professor carrega o caráter de ser considerada como uma atividade tipicamente feminina; (b) há evasão dos profissionais melhores preparados e, ao mesmo tempo, têm-se habilitado professores provenientes de classes sociais menos favorecidas, que buscam ascensão social por meio da profissão; (c) é considerada como uma atividade profissional inferior às demais, levando-se em conta o tratamento social, legal, institucional e econômico que lhe é conferido. Além desses fatores, é comum encontrarmos, também, concepções acerca da profissão docente como bico ou como uma vocação autêntica.

Pereira (1999) faz considerações no âmbito da discussão da formação docente. Segundo o autor, vários são os fatores externos ao processo pedagógico que vêm prejudicando a formação inicial. Sobre a escolha profissional docente comenta:

Sabe-se que o desestímulo dos jovens à escolha do magistério como profissão futura e a desmotivação dos professores em exercício para buscar aprimoramento profissional são conseqüências, sobretudo, das más condições de trabalho, dos salários pouco atraentes, da jornada de trabalho excessiva e da inexistência de planos de carreira (PEREIRA, 1999, p. 111).

Segundo Gatti (1996), a imagem social que os professores apresentam de si mesmo é bastante contraditória. A autora revela que se, por um lado, os professores exaltam a gratificação exposta pelos pais e pelas crianças, por outro, apontam: o descaso das políticas sociais para com a educação; a falta de respeito e interesse dos alunos; a falta de comprometimento dos pais ou da família com a educação dos filhos; os baixos salários; a desvalorização sentida pela arbitrariedade com que inovações e reformas educativas são impingidas a eles e pelo sistema, e o sentimento de desvalorização revelado pelo entorno da escola em que trabalham.

Considerando a identidade como construída, e não dada, respaldada pela memória tanto individual quanto social, consideramos que o indivíduo somente se vê reconhecido nas suas relações sociais estabelecidas. Assim, é na vivência dessas contradições e implicações sócio-político-culturais e econômicas que o professor constrói a sua identidade profissional.

\section{Identificar-se como biólogo}

A identidade do naturalista vem sendo construída desde os primórdios da humanidade. Observar fenômenos naturais e procurar explicações para os mesmos foram sempre um 
desafio presente nos textos dos filósofos gregos que permanece até os dias atuais, atestado por outros autores.

No decorrer da história das pesquisas de fenômenos biológicos, os pesquisadores tiveram suas potencialidades de investigação ampliadas, por intermédio de inúmeros instrumentos. Esses permitiram desvendar a presença de inúmeras espécies antes desconhecidas.

A observação e o registro dos fatos da natureza, que eram os fazeres dos primeiros naturalistas, evoluíram para a experimentação, que tem, como pressuposto, a pesquisa planejada por meio de condições acordadas pelos próprios investigadores. No decorrer desse processo, a investigação foi se aperfeiçoando, surgiram diferentes especialidades de investigadores. Dos primeiros naturalistas aos pesquisadores atuais, um grande número de especialidades relativas à pesquisa de fenômenos biológicos foi sendo constituído. Botânicos, zoologistas, anatomistas, fisiologistas, geneticistas, entre outros, deram lugar a subespecialidades em cada área do conhecimento. Hoje, podemos falar de especialistas de uma dada espécie de ser vivo ou de uma determinada molécula celular.

Esse fazer das Ciências Biológicas, mesmo que tenha evoluído e se especializado, sempre despertou o interesse na busca de produção de novos conhecimentos. O mundo natural e sua dinâmica continuam a interessar os homens. Nesse universo das possibilidades de "descobrir" o desconhecido ou explicá-lo, insere-se o núcleo de formação da identidade do biólogo.

Se, no início das Ciências Biológicas, os seus achados foram restritos aos arquivos e revistas que interessavam somente aos pesquisadores, os conhecimentos hoje são difundidos largamente pelos meios de comunicação, como: televisão, internet, jornais, revistas, filmes, entre outros.

Desde cedo, a criança entra em contato com a exuberância da diversidade presente nos ecossistemas que compõem a Terra. Por outro lado, a imagem do "cientista do bem", que pesquisa os problemas da humanidade e procura resolvê-los, faz parte da representação desses pesquisadores presente nos contextos socioculturais em que vivem os alunos.

Atualmente, os pesquisadores buscam utilizar o conhecimento biológico e transformá-lo em tecnologias que melhorem a qualidade de vida. Seleção genética, cultura de tecidos vegetais, fermentação de alimentos, produção de combustíveis, animais e plantas transgênicos, diagnósticos precoces, terapias genéticas, entre outros, são temas presentes nas discussões dos cientistas que se apresentam nos noticiários e em programas específicos.

É no interior dessa intrigante busca pelo conhecimento potencializado pela mídia que se constrói a imagem de pesquisador em Biologia. Assim, o presente trabalho de investigação sobre concepções da profissão desenvolvidas num curso de formação inicial procurou analisar essas imagens, bem como as referentes à profissão docente, recorrendo ao referencial teórico da semiótica peirceana.

\section{O referencial da Semiótica Peirceana}

Por intermédio da semiótica, podemos inferir como se dá o processo de cognição. Para Peirce (1839-1914), há uma estreita ligação entre percepção e conhecimento. Cognição e 
Brando, F. R.; Caldeira, A. M. A.

percepção são inseparáveis das linguagens por meio das quais os homens pensam, sentem, agem e comunicam-se.

Santaella (1993) explica que, na relação percepção e processo cognitivo, Peirce não deve ser entendido como racionalista, pois, para o autor, a percepção envolve também elementos não cognitivos e elementos inconscientes. Para a autora:

O bem da verdade, a maior parte do processo perceptivo está irremediavelmente fora do nosso controle. Só alcançamos controle sobre a percepção no momento em que o percepto é interpretado. Apenas então é que se podem fazer experimentos perceptivos, só então a percepção pode ser testada, criticada, modificada etc. (SANTAELLA, 1993, p. 17)

Portanto, por meio da percepção é que se dá o conhecimento, uma vez que é na percepção que reside toda a potencialidade geradora de interpretantes.

Para Peirce, o conhecimento é derivado de nossa experiência mediata de mundo, por meio de signos, a partir de outros conhecimentos já adquiridos de forma mais simples, num processo contínuo, denominado semiose. Utilizando o conceito do próprio Peirce, semiose é "o processo no qual o signo tem um efeito cognitivo sobre o intérprete" (CP 5.484) ${ }^{3}$.

O fundamento da semiótica peirceana centraliza-se no conceito de signo e na ação do signo, correspondendo a diferentes formas de representação. É baseada na convicção de que a relação sígnica é fundamentalmente triádica, isto é, pautada na relação entre signo (representamen), objeto e interpretante.

Peirce desenvolveu estudos pelos quais concluiu que todos os fenômenos, ou qualquer experiência, que se apresentam à percepção e à mente, tudo que aparece à consciência, ocorre numa gradação de três propriedades, as quais denominou de: Primeiridade, Secundidade e Terceiridade. Define fenômeno, palavra derivada do grego Phaneron, que significa qualquer coisa que, de algum modo e em qualquer sentido, aparece à percepção e à mente: "Por faneron [fenômeno] eu entendo o total coletivo de tudo aquilo que está de qualquer modo presente na mente, sem qualquer consideração se isto corresponde a qualquer coisa real ou não" (CP 1.284).

Assim, para Peirce, "primeiridade é o modo de ser daquilo que é tal como é, positivamente e sem referência a outra coisa qualquer" (CP 8.328). É como um primeiro olhar sobre algo, um sentimento sem reflexão, o que está na consciência em um simples momento, uma primeira apreensão das coisas sem estabelecimento de relações, um primeiro contato com as coisas, de uma forma imprecisa e indeterminada.

Secundidade está relacionada à idéia de ação e reação, conflito com o real. Qualquer sensação torna-se secundidade quando envolve a ação de um sentimento sobre o sujeito e expressa a reação específica dele (sujeito).

${ }^{3}$ Conforme convenção para a obra de Peirce, CP identifica os Collected Papers; os números indicam o volume, seguindo-se os parágrafos (HARSTONE, C.; WEISS, P.; BURKS, A. (Eds.). Collected papers of Charles S. Peirce. Cambridge, MA: Harvard University Press, 1931-1958. 8 vols. 
Investigação sobre a identidade profissional...

Terceiridade diz respeito à generalidade, corresponde à camada da inteligibilidade, ou seja, pensamentos em signos, por meio da qual representamos e interpretamos o mundo (SANTAELLA, 1983).

Sendo assim, "o signo é um primeiro (algo que se apresenta à mente), ligando um segundo (aquilo que o signo indica, se refere ou representa) a um terceiro (o efeito que o signo irá provocar em um possível intérprete)" (SANTAELLA, 2002, p. 7).

É na mente do intérprete que ocorre a representação, o que denominamos interpretante. Interpretante é o efeito interpretativo produzido em uma mente real ou potencial.

Santaella (1983) conclui que o significado de um signo é um outro signo, e esclarece que o signo tem dois objetos (imediato e dinâmico) e três interpretantes (imediato, dinâmico e final). O objeto dinâmico é o que o signo substitui, e o objeto imediato diz respeito ao modo como o objeto dinâmico está representado no signo, na mente do intérprete (SANTAELLA, 1983).

Citando Santaella (2002, p. 15):

O modo como o signo representa, indica, se assemelha, sugere, evoca aquilo a que ele se refere é o objeto imediato. Ele se chama imediato porque só temos acesso ao objeto dinâmico através do objeto imediato, pois, na sua função mediadora, é sempre o signo que nos coloca em contato com tudo aquilo que costumamos chamar de realidade.

O interpretante imediato é o potencial interpretativo do signo, ou seja, aquilo que o signo está apto a produzir numa mente interpretadora qualquer (SANTAELLA, 2002, 1983).

O interpretante dinâmico refere-se ao efeito efetivamente produzido em um intérprete pelo signo, isto é, o efeito singular que o signo produz em cada intérprete particular. De acordo com as categorias de primeiridade, secundidade e terceiridade, este interpretante subdivide-se em três, sendo eles: emocional, energético e lógico (SANTAELLA, 2002, p. 24).

O interpretante final, para Peirce: "É aquilo que seria finalmente decidido se a interpretação verdadeira e se a consideração do assunto fosse continuada até que uma opinião definitiva resultasse [...] aquele resultado interpretativo ao qual cada intérprete está destinado a chegar se o signo for suficientemente considerado" (CP 8.184).

Os interpretantes imediato e final são de análise quase impossível, o primeiro por sua natureza de gerar interpretantes e, o segundo, por dificilmente termos uma interpretação suficientemente considerada.

Consideramos, portanto, as categorias do interpretante dinâmico para a presente análise. $\mathrm{O}$ interpretante emocional diz respeito ao primeiro efeito que um signo está apto a provocar em um intérprete, efeito este de aspecto qualitativo, podendo ser uma simples qualidade de sentimento. O segundo efeito causado pelo signo é o energético, e diz respeito a um ato no qual há algum dispêndio de energia. Essa energia pode ser uma reação muscular em relação ao mundo exterior, pois os objetos físicos, que agem sobre nós e sobre os quais agimos, oferecem certa resistência às nossas manipulações; ou pode ser esforços interiores, atos de imaginação, pois as fantasias e imagens do nosso mundo interior, mesmo sendo frágeis à manipulação e mudança, também oferecem alguma resistência durante certo período de tempo (PEIRCE, 1983). O interpretante lógico foge à natureza do signo, constituindo-se num novo hábito de 
Brando, F. R.; Caldeira, A. M. A.

ação, mas que pode ser expresso por várias linguagens. É o pensamento ou entendimento geral produzido pelo signo. Sobre interpretante lógico e hábito, Peirce (1983, p. 131) discorre:

[...] Pode provar-se que o único efeito mental que pode ser assim produzido e que não é um signo, mas é de aplicação geral é uma mudança-de-hábito; entendendo por mudança-de-hábito uma modificação nas tendências de uma pessoa para ação, que resulta de exercícios prévios da vontade ou dos atos, ou de um complexo de ambas as coisas.

Com base nesse referencial e utilizando as categorias do interpretante elaboradas por Peirce, buscamos avaliar quais elementos oriundos do imaginário, da vivência acadêmica, do confronto de idéias contribuíram ou não no identificar-se como professor.

Esse referencial se mostra como possibilidade profícua para ancorar pesquisas da área que, muitas vezes, encontram dificuldades em obter suportes de análises que permitam ao pesquisador dialogar com um sistema de representação teórico dos fenômenos e o objeto que investiga.

\section{Metodologia}

O problema de pesquisa discutido, a escolha de atuação profissional de alunos do curso de Licenciatura em Ciências Biológicas de uma universidade pública do Estado de São Paulo, nos foi suscitado no decorrer do estágio-docência, realizado junto à disciplina de Didática do curso, quando percebemos, por meio de depoimentos dos alunos, algumas indagações em relação à escolha profissional. Nossa percepção inicial era de que esses alunos, que tinham optado por um curso de licenciatura, estavam se identificando com um curso de bacharelado que os formasse em algum ramo da pesquisa de conteúdos específicos de Biologia, e não enquanto professores. Essa percepção inicial nos permitiu elaborarmos essa investigação com o intuito de aprofundarmos a questão.

Os estudos sobre o referencial da semiótica peirceana nos permitia indagar a natureza dos diagramas mentais que os alunos estavam construindo a respeito da sua profissão. Seriam eles de fundo emocional, idealizado e pouco confrontado com a realidade da profissão escolhida? Ou seriam eles reforçados no confronto com as atividades do curso? Enfim, que interpretantes seriam possíveis de serem engendrados com o curso em questão?

Para consecução dos objetivos propostos na presente pesquisa, precisávamos levantar quais eram os interpretantes acerca da profissão escolhida que se faziam presentes no momento da entrevista com esses alunos. Utilizamos o recurso de uma imagem que trazia relações estereotipadas de prováveis atuações do biólogo e do professor. A idéia, na utilização desse recurso, foi não só de levantar concepções, mas, também, suscitar outras relações que, por ventura, pudessem construir no momento da coleta de dados. Assim, as imagens comportaram-se como signos que poderiam desencadear um processo dinâmico de interpretação na mente dos receptores, os alunos em questão, gerando interpretantes acerca desses signos (diagramas representativos da profissão e aqueles anteriormente presentes na mente dos entrevistados), produzindo um processo de "ação do signo", a semiose. 
$\mathrm{Na}$ ocasião, foram entrevistados seis alunos que frequentavam o sexto termo da Estrutura Curricular-Diurno e cinco alunos que frequentavam o quarto termo da Estrutura Curricular-Noturno do referido curso que, convidados nas salas de aulas para participar desta pesquisa, partilharam conosco momentos de sérias reflexões sobre o curso de Licenciatura em Ciências Biológicas.

$\mathrm{Na}$ tentativa de explicitar, de maneira estereotipada, as relações do biólogo com as principais atuações profissionais e seu contexto, representamos esse profissional de três maneiras: um biólogo atuando em ambiente natural, um biólogo atuando em laboratório, e um professor de Biologia.

A seguir, a imagem escolhida, em tamanho reduzido, que serviu como diagrama (signo) para a investigação.

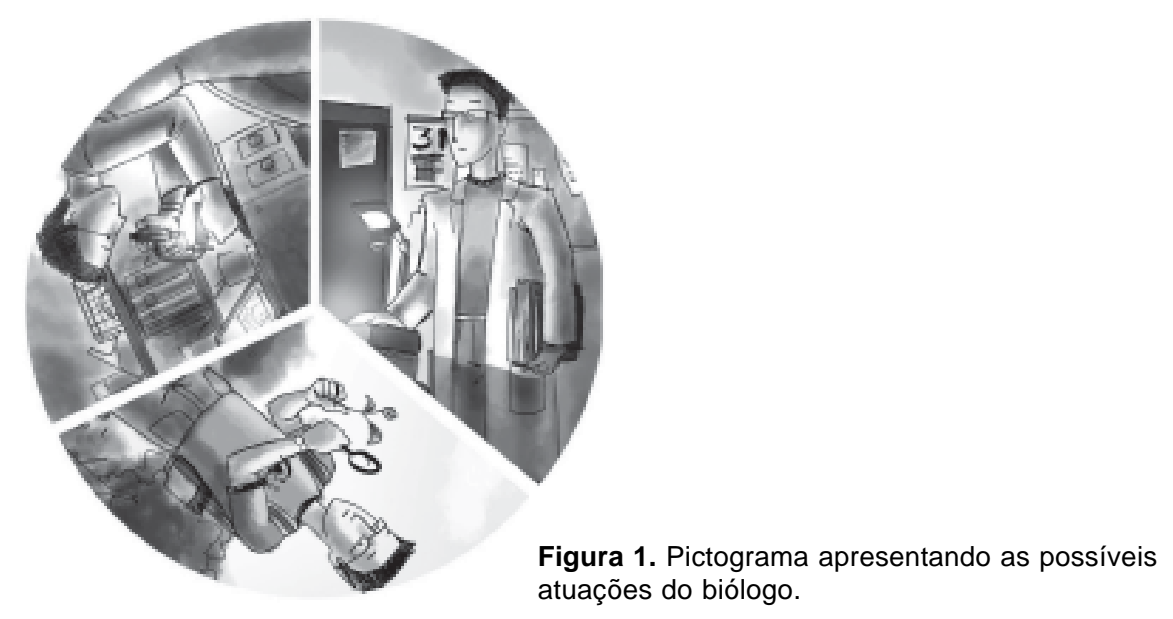

Concordamos que as imagens apresentadas são estereótipos de algumas possíveis atuações do biólogo. Contudo, pareceu-nos mais conveniente o uso das que apresentavam potencialidades de serem criticadas pelos alunos, oferecendo, assim, oportunidades de suscitar diversas interpretações.

As entrevistas foram realizadas individualmente, aluno e pesquisadora. Por se tratar de instrumento semiestruturado, em alguns momentos, foi necessária a formulação de perguntas não previstas e a reformulação de outras pertinentes a fim de potencializar respostas dadas pelos alunos entrevistados.

\section{Resultados e discussão}

Para realizarmos a análise semiótica acerca do nível de compreensão de identificação profissional, que os alunos do curso de Licenciatura em Ciências Biológicas construíram e 
Brando, F. R.; Caldeira, A. M. A.

continuaram a construir no decorrer do curso, recorremos a um conceito peirceano, que constitui pré-requisito à interpretação dos signos gerados.

Peirce (1983) relata que uma mente interpretadora (real ou potencial) que gera interpretantes a partir de um signo necessita, para parte dessa compreensão, de experiência colateral, a qual encontra-se fora do interpretante. O autor entende, por experiência colateral, a não intimidade com o sistema de signos, pois o que é inferido não pode apresentar-se como colateral, mas como uma "intimidade prévia com aquilo que o signo denota", ou seja, com aquilo que o signo representa.

Entendemos assim, que os alunos investigados apresentavam construções superficiais sobre o que o curso que escolheram, no exame de vestibular, poderia lhes oferecer. No entanto, essas suposições, ao entrarem em confronto com a realidade vivenciada no decorrer do curso, foram constituindo um conjunto de experiências colaterais específicas para cada aluno, em função das vivências dos mesmos, com maior ou menor intensidade, desenvolvidas: nos laboratórios, nas salas de aulas, nas pesquisas de campo, na biblioteca, nos encontros casuais, nas discussões entre os colegas, congressos e encontros, entre outras. Essas vivências foram permitindo que os alunos construíssem imagens da profissão de pesquisador de laboratório, de campo etc., e outra de professor.

As respostas que obtivemos dos respectivos alunos mostra-nos o nível de familiaridade possível de ser desenvolvida em função das experiências que tiveram, e continuaram tendo no decorrer do curso.

Os interpretantes gerados a partir das suas afirmações, evocando emoções, enfrentamentos e hábitos, podem ser discutidos à luz da teoria de Peirce.

Esses interpretantes (emocional, energético e lógico) podem ser "percebidos" pelo sujeito de forma conjunta, porque são processos mentais que ocorrem sem que tenhamos controle sobre os mesmos. A análise que "os separa" procura basear-se naqueles que se sobressaíram em relação aos outros, não deixando de considerar que os três modos pressupõem que haja a compreensão de todos, sem a qual o signo estaria degenerado.

A Tabela 1 traz as principais categorias construídas a partir das falas dos alunos em relação à atividade de pesquisa (em laboratório ou campo), classificadas segundo os interpretantes emocional, energético e lógico.

Os interpretantes gerados pelos alunos que evocavam uma qualidade de sentimento foram categorizados como interpretante emocional, baseando-se na descrição de Peirce (1983, p. 131) quando descreve que "o primeiro efeito significado de um signo é o sentimento por ele provocado $[\ldots] "$..

Observamos essa qualidade de sentimento quando os alunos relataram que gostavam de pesquisar e que não gostariam de parar de realizar pesquisas, mesmo que tivessem de desempenhar outras funções, como, por exemplo, a atividade docente. O sentimento de gostar ou não de algo é um interpretante emocional, pois o sujeito apenas remete a um sentimento sem oferecer nenhuma explicação ou estabelecer relação concreta sobre o sentimento evocado:

(5) "[...] eu gosto muito de estar em contato com a natureza [...] porque eu gosto muito de programa de conservação, de manejo, de ficar no meio do mato". 
Investigação sobre a identidade profissional...

Tabela 1. Categorias de interpretantes gerados pelos alunos em relação à atividade de pesquisa.

\section{INTERPRETANTE EMOCIONAL}

Gostar de pesquisar

Gostar da natureza

Gostar da vivência no laboratório

Evocar a figura do cientista

\section{INTERPRETANTE ENERGÉTICO}

Analisar os elementos presentes nas imagens e estabelecer relações entre os aspectos observados e suas construções abstratas

Recorrer à vivência para analisar a imagem

Atribuir qualidades para o pesquisador, p. e., investigativo

Inferir sobre a personalidade do pesquisador, p. e., feliz

Conferir "status" social à atividade de pesquisa

Associar a afinidade com a atividade laboratorial por conta do ingresso em respectivos estágios oferecidos nas disciplinas de conteúdo específico dispostas nos primeiros termos do curso

\section{INTERPRETANTE LÓGICO}

Afirmar que pesquisador é aquele que trabalha no campo ou laboratório

(8) "Por que eu não gosto de Botânica, sou insegura acho para dar aula. [...] Eu gostaria mais da parte de laboratório. Gostaria de atuar na genética blá, blá, blá, essa outra parte, que é uma coisa que eu gostaria de fazer".

Foram classificamos como energéticos aqueles interpretantes que, além de expressarem os sentimentos evocados pela atividade de pesquisa (laboratório ou campo), passaram a analisar os elementos que compunham as imagens observadas (o personagem, sua roupa, os objetos presentes), estabelecendo, dessa forma, relações entre esses e outros fenômenos. Neste sentido, quando os alunos emitiram afirmações, estipulando relações entre os aspectos observados nas imagens e suas construções abstratas, denominadas por Peirce de "experiência colateral", observamos um efeito de esforço mental envolvido na geração desses interpretantes, os quais Peirce chamou de interpretantes energéticos. Encontramos muitos exemplos de relações sendo estabelecidas a partir do confronto e da vivência cotidiana com o curso. Um exemplo:

(7) "Eu sempre gostei de plantas, gostei de observar as coisas, de cultivar plantinha, de pegar bichinho e ficar olhando. E sempre adorei muito Biologia, sempre me fascinou muito a vida, os mecanismos da vida. E eu sempre gostei dessa área de pesquisa, de ficar no laboratório vendo o que acontece com as coisas, é a parte que mais me fascina. Então é o que eu penso, é o que eu quero. Fiz. estágio o ano passado nessa parte de laboratório, gostei muito. Trabalhei com patologia, gosto muito de microorganismos, essa parte de biotecnologia, acho muito fascinante". 
Brando, F. R.; Caldeira, A. M. A.

Podemos inferir que, quando as imagens da representação do biólogo atuando em laboratório ou em ambiente natural foram apresentadas, os alunos atribuíram a este profissional, além das características presentes na imagem, outras que se relacionavam com as concepções que carregavam sobre a imagem de biólogo pesquisador, ou mesmo, com a imagem que faziam de si próprios como futuros biólogos, tais como: um indivíduo observador, com caráter investigativo; que promove e descobre novas coisas; jovem e feliz etc. Nesse sentido, os alunos estariam estabelecendo relações que faziam parte de suas idéias sobre as referidas atuações do biólogo.

Quando os alunos referiram-se a atividade de pesquisa realizada pelo biólogo, foi possível observar a posição de prestígio que esta atividade desperta na vida dos mesmos: (1) 'Para mim é interessante o 'status' que o laboratório às vezes me proporciona, eu acho. Acho interessante àquela coisa de jaleco, coisa branca, dentro do laboratório aqueles aparelhos ultra modernos, isso é uma coisa que é interessante e que motiva [...]”.

Consideramos, assim, que para o formando em Licenciatura em Ciências Biológicas é mais interessante o "status" proporcionado pela atividade laboratorial do que aquele proporcionado pela atividade docente. Isso é compreensível pois, como afirma Romero (1997), o ensino nos dias atuais é visto como uma atividade profissional inferior às demais, ainda mais quando levamos em conta o tratamento social, legal, institucional e econômico que lhe é atribuído.

Interpretantes energéticos foram gerados quando se referiram à participação em estágios desenvolvidos nos laboratórios, subsidiados por disciplinas específicas. Os alunos associaram a afinidade com a atividade laboratorial a partir do ingresso nos respectivos estágios, muitas vezes oferecidos no início do curso, tendo em vista que a estrutura curricular do mesmo, em seus primeiros termos (semestres), é formada por disciplinas de conteúdos específicos. A seguir, temos um dos exemplos no qual fica claro o exposto:

(3) "Não sei se eu me vejo [desenvolvendo pesquisa laboratorial], porque eu comecei a fazer estágio, o estágio me levou para o laboratório, eu acho que é um caminho que eu gostei. Então eu não parei para pensar: 'Vou para o laboratório', não é uma coisa que eu tinha já pré-concebida que queria trabalhar num laboratório. Aconteceu quando eu entrei na faculdade, e eu gostei e não penso em fazer outra coisa diferente".

Sobre os interpretantes gerados pelos alunos em relação à atuação do biólogo em laboratório ou em ambiente natural, observamos que nem todos chegaram ao nível de interpretante lógico, o qual é entendido, de acordo com Peirce, como uma regra geral, uma mudança de hábito interiorizada pela mente do intérprete. Entendemos como interpretante lógico as proposições colocadas que nos permitiram avaliá-las como constituição de um novo hábito adquirido, uma idéia geral formada a partir de vivências experienciadas pelos indivíduos, ou seja, quando os alunos fizeram escolhas convictas por uma das imagens apresentadas, e não mais simplesmente confrontavam idéias e vivências. São hábitos formados a partir de uma identidade profissional mais estruturada.

(11) 'Porque eu fiz. Biologia motivado pela questão mais do pensamento ecológico, tentar trabalhar com Educação Ambiental, trabalhar com ação direta no campo, trabalhar na área de Ecologia mesmo. Então, trabalhar direto em unidade de conservação, fazer trabalho de campo e acampar, uma 
Investigação sobre a identidade profissional...

coisa que eu sempre associei ao biólogo e que sempre foi a coisa que mais me motivou a ir para a Biologia”.

Foi possível perceber, nas concepções de alguns alunos, que o caráter de "pesquisador" só é atribuído aos alunos ou profissionais que desenvolvem pesquisa em laboratórios ou em ambiente natural. Quanto àqueles que desenvolvem pesquisa em ensino, por exemplo, não lhes é atribuído este título.

(4) "Na Biologia é muita pesquisa que faz, além de ser um professor, por exemplo, que pode dar aula; mas eu acho mais legal a parte da pesquisa mesmo".

(10) "A maioria quer trabalhar em um laboratório [quando sair da faculdade], quer mexer com microscópio. Eu acho que microscópio é um instrumento bem característico do biólogo [...]".

(6) '[...] Mas eu acho que trabalhar com pesquisa [referindo-se à atividade laboratorial] é o mais legal, você desenvolve alguma coisa, publica e faz um bem para a comunidade pesquisando. Eu acho que é um jeito legal de fazer um bem para a comunidade, de produzir alguma coisa".

A Tabela 2 evidencia as principais categorias classificadas como interpretantes emocional, energético e lógico, construídas a partir das falas dos alunos em relação à atividade docente:

Tabela 2. Categorias de interpretantes gerados pelos alunos em relação à atividade docente.

\section{INTERPRETANTE EMOCIONAL}

Gostar de ensinar

Gostar de se comunicar

Gostar de explicar

Gostar de estar rodeado de pessoas

\section{INTERPRETANTE ENERGÉTICO}

Relacionar o curso de licenciatura permitindo mais atribuições profissionais que o curso de bacharelado Relacionar que poderiam talvez conciliar pesquisa com a licenciatura

Expressar que, se necessário, dariam aulas como bico

Expressar timidez e vergonha em dar aula

\section{INTERPRETANTE LÓGICO}

Afirmar que o professor precisa estar preparado para a função de ensinar Definir a profissão como bico 
Inferimos que os alunos, em sua maioria, evidenciaram emoções e sentimentos quando se referiram à imagem do professor, o que denota uma presença marcante de interpretantes emocionais em relação a essa atuação do biólogo. Os sentimentos de "gostar" e/ou de volição estão muito presentes e evidentes em suas falas: (9) "[...] Para mim en adoro, porque en faço monitoria e quando eu vejo que alguém entendeu o que eu expliquei fico super feliz. [...]"; (1) "Eu gosto muito de comunicação, en adoro falar. Então, eu gosto de explicar e en gosto de me ver rodeado de pessoas interessadas no que eu estou falando [...] Eu gosto disso e isso eu acho interessante [...]".

Percebemos que, mesmo aqueles que pretendem trabalhar com pesquisa, em suas futuras atuações profissionais, quando se referiram ao magistério, evidenciaram sentimentos em relação à profissão docente que estão fortemente ligados à concepção de cuidado e ajuda ao próximo. Como Gauthier (1998) relata, para o ofício de professor não basta somente saber o conteúdo, ter conhecimento cultural abrangente, ter domínio sobre os alunos, entre outras colocações do senso comum. Diante da análise dos interpretantes emocionais evidenciados, acrescentamos que não basta gostar de se comunicar, ter vontade de "transmitir" conhecimentos, gostar de estar em contato com as pessoas e querer ajudar o próximo. Não podemos perder de vista o "reservatório de saberes" deste ofício citado pelo autor.

Quando os alunos estabeleceram relações entre suas vivências pessoais e experiências adquiridas no ambiente acadêmico, encontramos aqueles que, apesar de não apresentarem afinidade com a atividade docente, querem desenvolvê-la se conciliada com outros tipos de atividades, tais como pesquisa em laboratórios ou em ambiente natural. $\mathrm{O}$ estabelecimento dessas relações nos remete à idéia de confronto, conflito com o real ao qual Peirce se refere quando explica o interpretante energético. Nesse sentido, quando os alunos se referiram à escolha por um curso em licenciatura, deixaram evidente que essa tinha sido realizada com a intenção de ampliar sua atuação profissional, uma vez que, se tivessem optado pelo bacharelado, não poderiam desempenhar legalmente a função docente que os permitiria uma forma inicial de sustento: (9) '[...] Eu fiz licenciatura porque me falaram que, não que ela era melhor, mas que ela era mais abrangente do que o bacharelado. Com a licenciatura você tem as mesmas funç̃es que um bacharel e ainda por cima você pode dar aula, você está licenciado para isso [...]”; (11) "[...] Eu já tinha uma idéia de licenciatura e bacharelado antes, e eu sabia que fazendo licenciatura eu também poderia fazer pesquisa como um bacharel faz: Só que eu sendo bacharel não poderia ficar dando aula em ensino público, por exemplo [...]".

Outros comentaram a possibilidade de atuarem na atividade docente caso fosse necessário, e, neste sentido, conotando a palavra "necessário" à idéia de ajuda financeira, seja como uma atividade complementar, ou como um primeiro emprego quando saíssem da faculdade. Haguette (1991) problematiza essa questão analisando que aceitamos alguma atividade como "bico" quando não conseguimos um emprego melhor que nos garanta condições financeiras adequadas. Lembra que o "bico" geralmente não oferece satisfação pessoal e é considerado uma atividade transitória, que pode ser abandonada em qualquer momento quando nos for oferecida outra oportunidade melhor de trabalho.

Ainda enquanto estabeleciam relações entre o curso frequentado e a idealização sobre o futuro profissional, houve aqueles que demonstraram não ter afinidade com a docência. Essa demonstração envolve a ação de um sentimento sobre o sujeito e expressa sua reação específica, assim como ensina Peirce sobre Secundidade, e é aplicada ao interpretante energético. Os alunos apontaram fatores como timidez, vergonha e medo em se expor diante das pessoas como obstáculos para seguir a carreira docente. 
Investigação sobre a identidade profissional...

Em relação à profissão docente, os alunos formularam idéias que nos remetem ao pensamento ou entendimento geral produzido pelo signo, uma análise crítica, podendo constituir um novo hábito de ação, o que é explicado por Peirce como interpretante lógico. Nesse sentido, as falas dos alunos revelaram—nos uma visão reducionista sobre os saberes inerentes à atividade docente, sobretudo os saberes das Ciências da Educação e os Saberes da ação pedagógica, explanados por Gauthier (1998). Analisamos que os alunos limitaram-se apenas às críticas em relação: às disciplinas e aos conteúdos pedagógicos; à importância de estágios realizados em práticas de ensino e aos seminários, como elementos importantes na formação docente; aos professores e suas formas de atuação em sala de aula:

(4) "Por exemplo, aqui você vai aprender genética, você vai aprender tudo da genética, mas se você for passar para uma criança, um adolescente de quinze anos, você não vai explicar detalhadamente, você vai ter que explicar só o básico. Ai esse básico não é passado assim: como você deve dar aula, o que você deve passar para o seu aluno. Eles só ensinam tudo, ai você tem que ver o que você deve passar. Acho que falta isso de preparar melhor o professor".

Podemos verificar, por meio dessa fala, que o aluno analisa a pouca relação entre as disciplinas básicas e o compromisso com a formação do futuro professor. Aponta as dificuldades que poderá enfrentar ao ter de exercitar a transposição didática somente quando estiver dando aula e sem o apoio dos professores da universidade.

Durante a entrevista, quando indagados sobre a escolha por um curso de Licenciatura em Ciências Biológicas, muitos se remeteram à afinidade com disciplinas ou professores da área biológica que fizeram parte de suas formações, durante os Ensinos Fundamental e Médio, citando-os como forte influenciadores da escolha profissional que fizeram. Entendemos que os interpretantes lógicos gerados estavam fortemente amparados na concepção de que o fazer das Ciências Naturais desperta maior interesse nas pessoas por carregar consigo o caráter de busca, descoberta e produção de novos conhecimentos: (6) "Eu escolbi a Biologia, não escolbi a licenciatura. Por que eu sempre gostei de Biologia, o que ajudou bastante foram os professores que en tive no colegial, que eles sempre foram muito legais, sempre deram chance para a gente querer aprender mais. Eu tinha aula de laboratório também, aula prática".

Percebemos a influência dos professores de Educação Básica como decisivos na sua escolha para o curso de Ciências Biológicas.

Categorizamos, como interpretante lógico, os interpretantes gerados em relação à futura atuação profissional (como docentes) a ser desempenhada como "bico"4. Porém, destacamos que assim os entendemos diferentemente das falas destacadas anteriormente, pois, nesse momento, os interpretantes gerados evidenciaram-nos uma posição de atitude a ser realmente efetivada quando fosse concluído o referido curso.

\footnotetext{
${ }^{4}$ Os alunos referiram-se à profissão como bico de duas formas diferentes. Na primeira entendiam aquilo como uma possibilidade, se necessário fosse, e na segunda entendiam o bico como um hábito adquirido, classificando a profissão de professor como tal.
} 
Brando, F. R.; Caldeira, A. M. A.

(8) '[...] Mas hoje em dia, eu caí um pouco na real que, quando você se forma em Biologia, biólogo, o primeiro emprego que vai te aparecer com certeza vai ser lecionar. Mas eu não vejo isso pro meu futuro, entendeu? Eu posso ver isso para agora, por exemplo, eu vou me formar o ano que vem, então eu vejo isso pra agora, mas para um futuro eu não gostaria [...]".

A imagem do biólogo atuando como professor foi escolhida por uma minoria dos alunos. Transcrevemos, a seguir, uma fala evidenciando o interpretante lógico gerado a partir do questionamento feito durante a entrevista relativa às imagens que melhor representariam a profissão que tinham escolhido:

(2) "Como professor. Apesar de eu gostar um pouco de pesquisa, mas eu entrei na faculdade com intenção de serprofessor mesmo. Não escolbi licenciatura por ser o curso que era menos concorrido, ou menos vaga, não. Escolbi licenciatura e vim para cá só porque não deu certo na Unicamp, mas a minha busca é ser professor mesmo. Espero que dê certo".

Essa fala nos faz refletir que os alunos que queriam ser professores já tinham essa idéia antes de iniciar o curso de Licenciatura em Ciências Biológicas.

Respondendo aos objetivos propostos na pesquisa, sobretudo no que se refere a verificar se as concepções iniciais que os alunos possuíam sobre a profissão influenciaram na construção de sua identidade profissional, podemos responder que sim. O diagrama mental formado (emocionalmente ou logicamente) sobre a possibilidade de se tornar pesquisador nas áreas de Ciências Naturais foram evidenciadas e reforçadas pelas práticas realizadas no decorrer do curso. O mesmo não podemos afirmar sobre a construção da identidade de professor no curso de Licenciatura em Ciências Biológicas em questão. Percebemos que o referido curso não favorece essa construção pois: a) introduz precocemente os alunos em atividades laboratoriais sem que os mesmos, muitas vezes, tenham optado por elas; b) a estrutura curricular não articula áreas específicas com pedagógicas e o exercício de transposição didática fica restrito a uma das áreas somente; além disso, as disciplinas pedagógicas são oferecidas no final do curso quando muitos alunos já estão comprometidos com projetos de pesquisas nas áreas de conhecimentos específicos; c) alguns professores da área de conhecimentos específicos acabam por reforçar a idéia de cientista especialista na medida em que valorizam somente a construção de conceitos, e não o valor social de compartilhar os mesmos com outros níveis de educação formal e com a sociedade como um todo.

Os interpretantes (emocional, energético, lógico) que percebemos por meio das falas dos referidos alunos, representam aqueles que os mesmos engendraram em função das experiências vivenciadas até o momento da entrevista. O próprio ato de entrevistar pode gerar interpretações, assim como ao término do curso. O processo semiótico de geração de signos-pensamentos é contínuo e ininterrupto e, certamente, atualizado por uma mente que experiencia. 
Investigação sobre a identidade profissional...

\section{Considerações finais}

As análises realizadas nesta pesquisa permitiram-nos sistematizar algumas concepções iniciais dos alunos referentes ao curso de Licenciatura em Ciências Biológicas de uma universidade pública do estado de São Paulo.

Averiguamos que a opção por frequentar um curso de licenciatura não se trata, muitas vezes, de uma decisão convicta dos alunos, uma vez que parte deles relatou gostar e querer desenvolver, somente e "se possível", atividades de pesquisa, seja em laboratório ou em ambiente natural. Porém, após concluírem uma pós-graduação, alguns almejam conciliar atividades de pesquisa com a docência, ambas desenvolvidas no Ensino Superior. Percebemos que o fator determinante dessa escolha profissional é a pesquisa, pois, ao escolherem a docência no Ensino Superior, pressupõem o fato de que a mesma está atrelada à função de pesquisador.

Apontaram diferenças entre as modalidades bacharelado e licenciatura e, mesmo afirmando que gostariam de aprofundar seus estudos na área de pesquisa (bacharel), optaram pelo curso de licenciatura, devido à maior abrangência da mesma. Acreditam que esta formação oferece mais oportunidades de atuação no mercado de trabalho quando comparada ao bacharelado. De acordo com essa perspectiva, encontramos aqueles que encaram a profissão docente como "bico", pois somente lecionariam se fosse necessária uma ajuda no orçamento ou caso não tivessem outra oportunidade de emprego na área em que gostariam de atuar, como, por exemplo, no desenvolvimento de pesquisas. Lembramos que a pesquisa em ensino não é almejada ou tão cogitada pelos alunos, talvez por entendê-la somente como possibilidade de atuação didática, e não como possibilidade de se tornar pesquisador da própria prática ou de outras áreas de pesquisa no ensino.

Mesmo não sendo objetivo dessa pesquisa, podemos inferir a necessidade de aprofundarmos estudos sobre como a forma de atuação de um professor pode exercer influências sobre as escolhas futuras de seus alunos, visto que percebemos a influência dos professores de educação básica na escolha pelo curso de Ciências Biológicas. Assim, sugerimos que os professores das áreas de conhecimentos específicos dos cursos de licenciatura em Ciências Naturais deveriam refletir sobre como a sua docência contribui ou não para a formação identitária de professor em seus alunos. Seriam esses professores de Ensino Superior, de cursos de licenciatura em Ciências Biológicas, também alunos que, em sua graduação, buscaram a pesquisa em áreas de conhecimentos específicos e se refugiaram na docência de nível superior apenas para poder exercer a função de pesquisador nestas áreas? Não podemos responder essa pergunta, mas as influências dessas áreas específicas do conhecimento sobre os alunos são evidentes.

Alguns alunos evidenciaram que o engajamento, em pesquisas laboratoriais na própria universidade, logo no início do curso, foi uma forma de identificação com esse tipo de atividade e, assim, deixaram de priorizar atividades de ensino necessárias à profissão docente. Inferimos que além do possível papel influenciador do professor universitário, a estrutura curricular do referido curso favorece esse tipo de engajamento, visto que as disciplinas de conteúdos aplicados ao ensino são oferecidas aos alunos efetivamente a partir do $6^{\circ}$ e do $8^{\circ}$ termos da estrutura curricular do curso de Licenciatura em Ciências Biológicas - Diurno e Noturno, respectivamente, o que corresponde para ambos, o penúltimo ano. Sugerimos uma reorganização na disposição dessas disciplinas, ou, até mesmo, a inserção de outras disciplinas que favoreçam a ampliação do papel social do educador, assim como evidenciou um aluno em momento 
Brando, F. R.; Caldeira, A. M. A.

informal da entrevista, sugerindo disciplinas da área de ciências humanas, como Antropologia ou Sociologia, ou um trabalho que articulasse Ciência, Tecnologia, Sociedade e Ambiente.

Outro apontamento pertinente foi em relação às disciplinas de conhecimentos específicos, as quais, muitas vezes, segundo os alunos, não apresentam possibilidades de transposição didática para outros níveis de ensino. Acreditamos que isto dificulta o desenvolvimento, por parte dos alunos, dos saberes da ação pedagógica, os quais envolvem os saberes experienciais (toda experiência que o professor adquire ao longo de sua jornada docente, que, muitas vezes, fica intrínseca a ele) que deveriam ser externalizados pelos professores universitários, ou mesmo construídos conjuntamente com os alunos, para que estes pudessem tê-los como "modelo", uma vez que são professores em formação.

Ainda que não fosse objetivo deste trabalho, um "olhar cismado" sobre a metodologia da pesquisa realizada permite-nos afirmar que os instrumentos de investigação utilizados possuem potencialidades diversas de pesquisa, ou seja, permitem interfaces com outras áreas de saberes. A análise semiótica dos dados obtidos pela entrevista evidenciou-nos que os interpretantes engendrados pelos alunos estão imersos num mundo de significações, expressas pelos mesmos: na forma de sentimentos; na relação entre sua "experiência colateral" e as experiências vivenciadas dentro e fora do ambiente acadêmico, e nas concepções ou idéias gerais formadas acerca do curso de Licenciatura em Ciências Biológicas, as quais acabaram constituindo-se em leis que regeram, ou ainda regem, a postura e as colocações desses sujeitos. Após esta pesquisa, continuamos com a firme convicção de que o curso de licenciatura pesquisado pouco contribui para a construção de uma identificação dos alunos com a profissão de professor, e apesar de constituir-se em um curso de formação para tal, acentua a construção da imagem do cientista pesquisador nas áreas básicas da Biologia.

\section{Referências}

CIAMPA, A. Identidade. In: LANE, S.; CODO, W. (Orgs.). Psicologia social: o homem em movimento. 9. ed. São Paulo: Brasiliense, 1991. p. 58-75.

GATTI, B. A. Os professores e suas identidades: o desvelamento da heterogeneidade. Cadernos de Pesquisa, São Paulo, n. 98, p. 85-90, 1996.

GAUTHIER, C. et al. Por uma teoria da pedagogia: pesquisas contemporâneas sobre o saber docente. Trad. Francisco Pereira. Ijuí: Ed. UNIJUÍ, 1998.

HAGUETTE, A. Educação: bico, vocação ou profissão? Educação \& Sociedade, Campinas, v. 38, ano XII, p. 109-21, 1991.

PEIRCE, C. S. Escritos coligidos. Trad. Armando Mora D’Oliveira; Sérgio Pomerangblum. 3. ed. São Paulo: Abril Cultura, 1983.

PEREIRA, J. E. D. As licenciaturas e as novas políticas educacionais para a formação docente. Educação \& Sociedade, Campinas, v. 20, n. 68, p. 109-25, 1999. 
Investigação sobre a identidade profissional...

ROMERO, D. M. F. Tornar-se professor: reflexões sobre a construção da identidade profissional do professor do curso de magistério. Interações: estudos e pesquisas em Psicologia, São Paulo, v. 2, n. 3, p. 35-46, 1997.

SANTAELLA, L. Semiótica aplicada. São Paulo: Pioneira Thomson Learning, 2002.

A percepção. São Paulo: Experimento, 1993.

O que é semiótica. São Paulo: Brasiliense, 1983.

SILVA, E. T. Professores de $\mathbf{1}^{\mathbf{0}} \mathbf{g r a u}$ : identidade em jogo. Campinas: Papirus, 1995. 